\title{
Exploring the networks of government scientists using Social Network Analysis: a scoping study
}

\author{
Goggin, C.L. ${ }^{\text {a, b }}$, Cunningham, R. ${ }^{c}$, Summerell, G. ${ }^{\text {a }}$, Leys, J. ${ }^{\text {a }}$, Barrett, T. ${ }^{\text {a b }}$, Auld, T.D. ${ }^{\text {a }}$, Oliver, I. ${ }^{\text {a b }}$ \\ and M. Littleboy ${ }^{\mathrm{a}}$ \\ ${ }^{a}$ New South Wales Office of Environment and Heritage, Australia \\ Email:1ouise.goggin@environment.nsw.gov.au \\ ${ }^{b}$ School of Environmental and Rural Science, University of New England, Armidale, Australia \\ ${ }^{c}$ Social Network Associates, Australia
}

\begin{abstract}
Scientists working for the New South Wales (NSW) Office of Environment and Heritage (OEH) provide rigorous evidence and advice to support government priorities which include protecting the natural environment. They also collaborate with and attract non-government researchers to work on government priorities.
\end{abstract}

In this scoping study, we used Social Network Analysis (SNA) to visualise the ego networks of six government scientists from OEH who work on biodiversity conservation and landscape management. This allowed us to explore the potential reach of their advice and information within OEH and beyond; and examine gaps and redundancy in the stacked ego networks.

Each scientist exported contacts from Microsoft Outlook, and some also exported contacts from LinkedIn and ResearchGate. They added missing contacts from recall, then ranked contacts by frequency of contact in the previous year from: 0 times in the last year; 1-2 times; 3-6 times; 7-12 times; or $>12$ times. Ego networks of each scientist were analysed separately then stacked to determine reach and overlap. Analyses and visualisations were run in UCINET and Netdraw.

We found the six government scientists have connections with 980 unique contacts from 27 categories of organisations in Australia and overseas. So, although our sample represents only $3 \%$ of staff from the Science Division in OEH, the potential reach of their information and advice to other organisations is large.

Most contacts of the six scientists $(70 \%, n=691)$ were from beyond OEH of which only $10 \%$ were shared $(n=71)$. The majority of external contacts (34\%) were from universities in Australia and overseas $(n=235)$, and from research organisations $(\mathrm{n}=69)$ including CSIRO, Cooperative Research Centres and museums. Few of these contacts were shared. This reflects the diverse research interests of the scientists who collaborate with academics and researchers across Australia and overseas.

The scientists connect to a variety of organisations who influence land management in NSW, including Local Land Services $(\mathrm{n}=79)$ and councils $(\mathrm{n}=14)$. They also connect with many staff from National Parks \& Wildlife Service $(n=43)$. However, this represents only $2 \%$ of NPWS staff so may be a gap in the network of the scientists.

About one third of the contacts of the six egos $(30 \%, n=289)$ were from OEH with many of these contacts shared ( $40 \%$ of OEH contacts shared, $\mathrm{n}=115)$. Most overlap of contacts was in Science Division $(64 \%$ of Science Division contacts were shared, $\mathrm{n}=89$ ). Shared contacts are likely to allow information to flow through the network and contribute to shared knowledge. However, there may also be some redundancy in the connections within Science Division.

The six egos had 10\% of staff from Policy Division ( $n=7$ ) in OEH and 13\% of staff from Regional Operations $(n=66)$ in their network. So their advice and information potentially flows into government policy, and informs management of environmental threats.

The ego networks ranged from 115 to 360 total contacts, and varied from $32 \%$ to $69 \%$ internal (OEH) contacts. The more contacts the scientist had, the higher percentage of external contacts in their network.

Our scoping study allowed scientists to visualise their networks for the first time, so they could reflect on potential gaps and duplication across the group's network. This stimulated discussion about the implications for the organisation. The analysis also raised many questions which we will seek to answer with future research. For example, we are yet to determine whether the total number and diversity of contacts enhance the scientist's skills and capacity, and the reach and impact of their work.

Keywords: Social Network Analysis, scientists, government, knowledge 


\section{INTRODUCTION}

Government scientists must function as 'bridging agents' and facilitate learning between policy makers, managers, scientists and stakeholders (Roux et al. 2015). However, the challenges of sharing information and knowledge between different disciplines such as science and policy are well documented (Gibbons et al. 2008).

Social Network Analysis (SNA) has been used in many fields including social sciences (Borgatti et al. 2009) where it can identify patterns of communication (Crona and Bodin 2006). We wanted to explore the use of SNA to visualise the professional networks of government scientists and examine their communication contacts and the bridges they create between different disciplines.

The exchange of information and knowledge among stakeholders is fundamental to the effective management of natural resources (Crona and Bodin 2006). The New South Wales (NSW) Government employs scientists in the NSW Office of Environment and Heritage (OEH) to provide rigorous evidence and advice to support its priorities, which includes protecting the natural environment.

In this scoping study, we used SNA to visualise the ego networks of six scientists from OEH who work on biodiversity conservation and landscape management. The aim was to determine whether SNA could visualise the potential reach of advice and information from government scientists within the organisation and beyond, and highlight gaps and redundancy between different disciplines.

\section{METHODS}

At the time of our analysis, OEH employed staff in Science Division (198 staff), Policy (66), National Parks \& Wildlife Service (2050), Regional Operations (496) and Strategy, Performance \& Services Group (202). Many scientists in OEH are employed in Science Division which has seven Branches related to their function. The Ecosystem Management Science Branch (EMS) is mainly responsible for research and understanding of terrestrial ecosystems.

Six senior scientists (N1-N6) from EMS were selected for a scoping study of ego networks because of their diversity of research and their leadership roles in the organisation. Between August and October 2014, each participant exported professional contacts from Microsoft Outlook (Contacts, Frequent Contacts, Suggested Contacts) as csv files. In some cases, contacts from LinkedIn (N2, N3, N4, N6) and ResearchGate (N2, N4, N5) were also exported.

For each participant, the contacts (also called 'alters') from Microsoft Outlook, LinkedIn and ResearchGate were merged into a Microsoft Excel spreadsheet and cleaned (duplicates removed; spelling and organisations corrected). The cleaned Microsoft Excel spreadsheet of alters was returned to each participant who checked the list, added additional names from recall, and then ranked each name by frequency of contact in the previous year. Participants ranked contact with the alter from: Not at all ( 0 times within the last year); Infrequently ( 1-2 times within the last year); Somewhat infrequently ( $\sim 3-6$ within the last year); Somewhat frequently $(\sim 7-12$ within the last year); Frequently ( $>12$ within the last year). Alters who had not been contacted in the previous year were excluded from further analysis.

The final list of contacts from each scientist were allocated to one of 27 categories: Australian Government, company (with more than 200 employees), consultant (less than 200 employees), Cooperative Research Centre, local council, CSIRO, overseas government organisation, international, state government (Australian Capital Territory, NSW, Queensland, South Australia, Tasmania, Victoria, Western Australia), landholder, Local Land Service, media, museum, non-government organisation, professional association or organisation, researcher, Royal Botanic Gardens Trust, university, university overseas, and volunteer. Contacts from OEH were allocated to a Division or Group (Business Information Systems; National Parks \& Wildlife Service; Policy; Regional Operations; Science; Strategy, Performance \& Services Group). Contacts in OEH Science Division were allocated to one of seven Branches: Climate \& Atmospheric Science (CAS); Divisional Coordination, Strategy \& Performance (DCSP); EMS; Environment Protection Science (EPS); Native Vegetation Information Science (VIS); Science Strategy (SS); and Water, Wetlands \& Coasts (WWC).

Each ego network was analysed separately, then stacked with the other five ego networks to determine overlap between networks. Analyses and visualisations were run in UCINET (Borgatti et al. 2002) and Netdraw (Borgatti 2002). For each ego, the visualisation was forced to group by attribute, i.e. category. For stacked egos, the visualisations were created using Euclidean distance, i.e. the most central nodes in the centre of the image and less central nodes towards the periphery. In some visualisations, pendants (a node which is connected to one ego and no other) were deleted to simplify the visualisation. 


\section{RESULTS}

Social Network Analysis of the ego networks of six scientists from Science Division in OEH revealed their network includes 980 contacts (Table 1) from 27 categories of organisations in Australia and overseas.

The majority of contacts of the six scientists were from external organisations $(70 \%, \mathrm{n}=691)$, and were unique to one scientist ( $90 \%$ of external contacts, $\mathrm{n}=620$ ) (Figure 1, Figure 3 ). The majority of external contacts of the six scientists were from universities in Australia and overseas $(n=235)$, followed by NSW Government departments (excluding OEH) $(\mathrm{n}=87)$, other government departments from Australia and overseas $(\mathrm{n}=87)$ and Local Land Services $(\mathrm{n}=79)$ (Table 1). Most contacts from universities $(\mathrm{n}=221,94 \%), \operatorname{CSIRO}(\mathrm{n}=31,74 \%)$, museums $(\mathrm{n}=6$, $86 \%)$ and $\mathrm{CRCs}(\mathrm{n}=2,67 \%)$ were unique to one scientist.

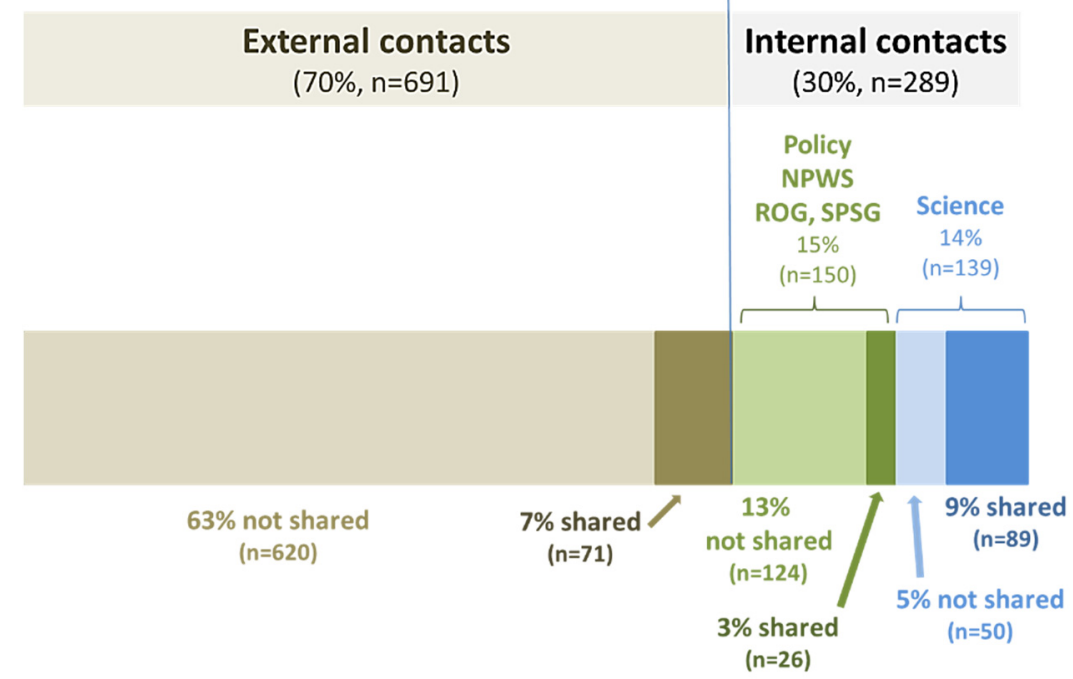

Figure 1. Number of external and internal contacts of the six egos (with duplicates removed), with percentage and number of contacts shared by one or more egos. NPWS = National Parks \& Wildlife Service; ROG = Regional Operations Group; SPSG = Strategy, Performance \& Services Group in OEH.

About a third of the contacts of the six egos were from OEH $(30 \%, \mathrm{n}=289)$ with less than half of those contacts $(40 \%, n=115)$ shared by two or more of them. The majority of OEH contacts of the six scientists were from Science Division (139 unique contacts; 64\% of all staff in Science Division), then Regional Operations Group (66; 13\% of all staff in ROG), National Parks \& Wildlife Service (43; $2 \%$ of all staff in NPWS), Strategy, Performance \& Services Group (22; 10\% of staff in SPSG) and Policy ( $7 ; 10 \%$ of all staff in Policy). The number of staff in each Group and Division in OEH is different, so the scientists are connected to a different proportion of staff from each Group and Division. For example, $10 \%$ of staff from both SPSG and Policy were in the network of the six egos, represented by 22 and seven staff respectively.

Most of the shared contacts of the six egos were OEH contacts from Science Division (64\% of contacts in Science Division shared, $n=89$ ). The six scientists share fewer contacts in OEH beyond Science Division ( $3 \%$ of total contacts and $17 \%$ of OEH (excluding Science) were shared; n=26) (Figure 1, Figure 4).

The size of individual ego networks ranged from a total of 115 contacts from 10 categories (N1) to 360 contacts from 19 categories (N3), and from $32 \%(\mathrm{~N} 2)$ to $69 \%(\mathrm{~N} 1)$ internal contacts. The three egos with the most contacts $(\mathrm{N} 3, \mathrm{n}=360 ; \mathrm{N} 2, \mathrm{n}=294 ; \mathrm{N} 5, \mathrm{n}=224)$ also had the lowest percentage of internal contacts (32-36\%) (Figure 2). There is a strong positive linear relationship between the number of external contacts and total number of contacts (slope of regression line $=0.82$ ). There is insufficient data to determine whether the number of contacts in Science Division or in other OEH Groups and Divisions varies with the total number of contacts.

Most frequent contact for all six egos $(\geq 15, \mathrm{n}=27$ ) was with staff from their own Branch ( $\mathrm{n}=18$ which includes the six egos), three (of seven) other Branches in Science Division (Science Strategy, $\mathrm{n}=3$; Divisional Coordination, Strategy \& Performance, DCSP, $\mathrm{n}=3$; Vegetation Information Science, VIS, $\mathrm{n}=2$ ) and the Executive Director of the Division ( $n=1$ ) (Figure 4). This represents $37 \%$ of staff from EMS, $27 \%$ staff from Science Strategy, $18 \%$ staff from DCSP and $7 \%$ of staff from VIS. 


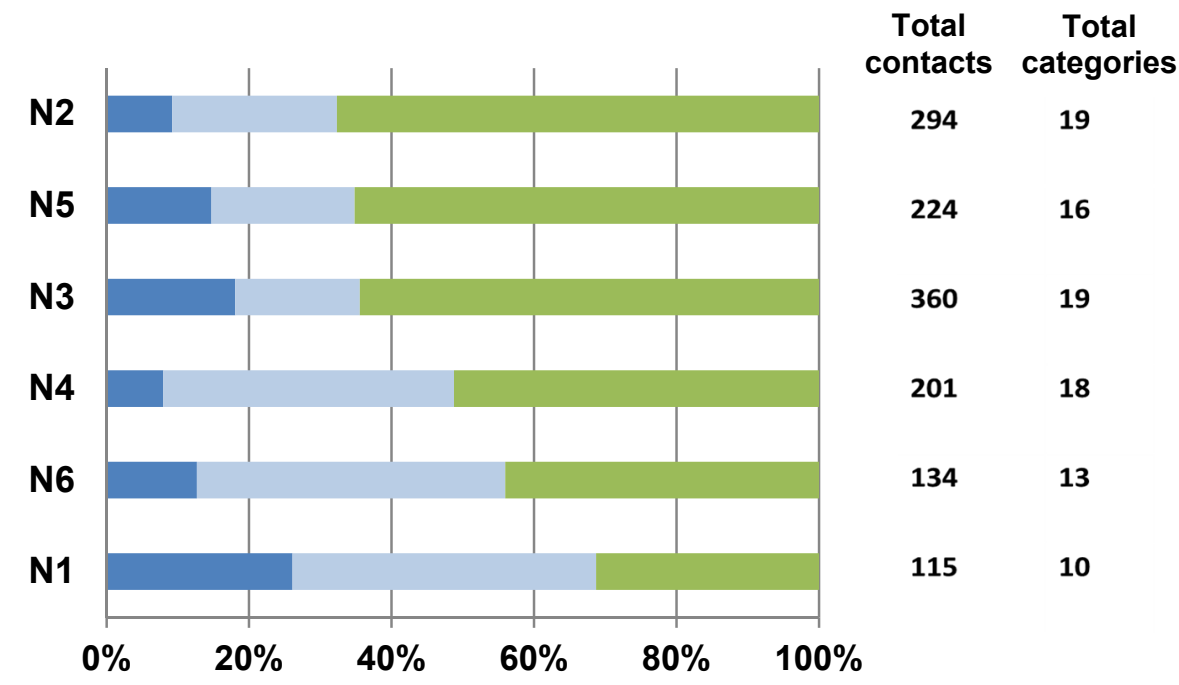

Figure 2. Total number of contacts of each ego (N1-N6) with the total number of categories of contacts (where all OEH contacts were counted as one category), percentage of internal (OEH excluding Science in dark blue, OEH Science Division in pale blue) and external (green) contacts.

\section{DISCUSSION}

In their combined network, the six government scientists in this scoping study connected with 980 unique contacts from 27 categories of organisations in Australia and overseas. So although our sample represented only 3\% of staff from Science Division in OEH, the potential reach of their information and advice is large.

The scientists with more contacts had a higher percentage of external contacts in their network. Transformational adaptors (those who undertake major purposeful action resulting in significant changes in structure or function) actively seek ties with individuals "outside their peer groups, geographical locations and industry boundaries" (Dowd et al. 2014), suggesting the three egos with higher percentages of external contacts (N2, N3, N5) may be more likely to implement novel strategies and options. We are yet to confirm this suggestion.

The high proportion of contacts from universities and research organisations in the network reflects their collaborative research with academics and researchers across Australia and overseas. There was little overlap in external contacts of the six scientists from universities and research organisations. This reflects their diversity of research which ranges from landscape health; land use and planning; fire ecology and risk management; assessing impacts and enhancing capacities to adapt to climate change; threatened and native species conservation; ecological management of pests and invasive species; and restoring biodiversity and ecological processes.

The scientists connect to a variety of organisations that influence land management in New South Wales, including Local Land Services and local councils. There is a potential gap in influence with only $2 \%$ of staff from National Parks \& Wildlife Service (NPWS) in their network. NPWS manages about $9 \%$ of land in NSW in Parks and reserves. About half (48\%) of the 43 NPWS staff in their network were regional or area managers or team leaders so the low percentage may not reflect the influence of these contacts.

The minority of contacts of the six scientists were from OEH and many contacts were shared, with most overlap and most frequent contact with staff in Science Division. According to Borgatti et al. (2009), strong ties tend to be "clumpy" in that one's close contacts tend to know each other - and "some of the information they pass along is redundant." This suggests there may be some redundancy in the network of the six scientists in Science Division.

Crona and Bodin (2006) found strong social networks facilitate the generation, acquisition and diffusion of knowledge and information. The optimal network structure to spread factual, especially tacit, knowledge is cohesion (high density) (Long et al. 2013). So it is likely the networks in Science Division with many shared contacts and frequent contact allow information to flow through the network and "contribute to shared knowledge, practices and norms" (Dowd et al. 2014). However, strong networks can also reinforce social norms and hinder transformational change (Dowd et al. 2014), prevent acquisition and sharing of new knowledge, and homogenise knowledge and experiences in the network (Crona and Bodin 2006).

Successful research-policy partnerships are built around personal relationships (Gibbons et al. 2008). The six scientists in this study had 10\% of staff from Policy Division in their combined network, suggesting their scientific knowledge has the potential to flow into government policy. Haynes et al. (2011) also found researchers who 
Goggin et al., Exploring the networks of government scientists using Social Network Analysis: a scoping study

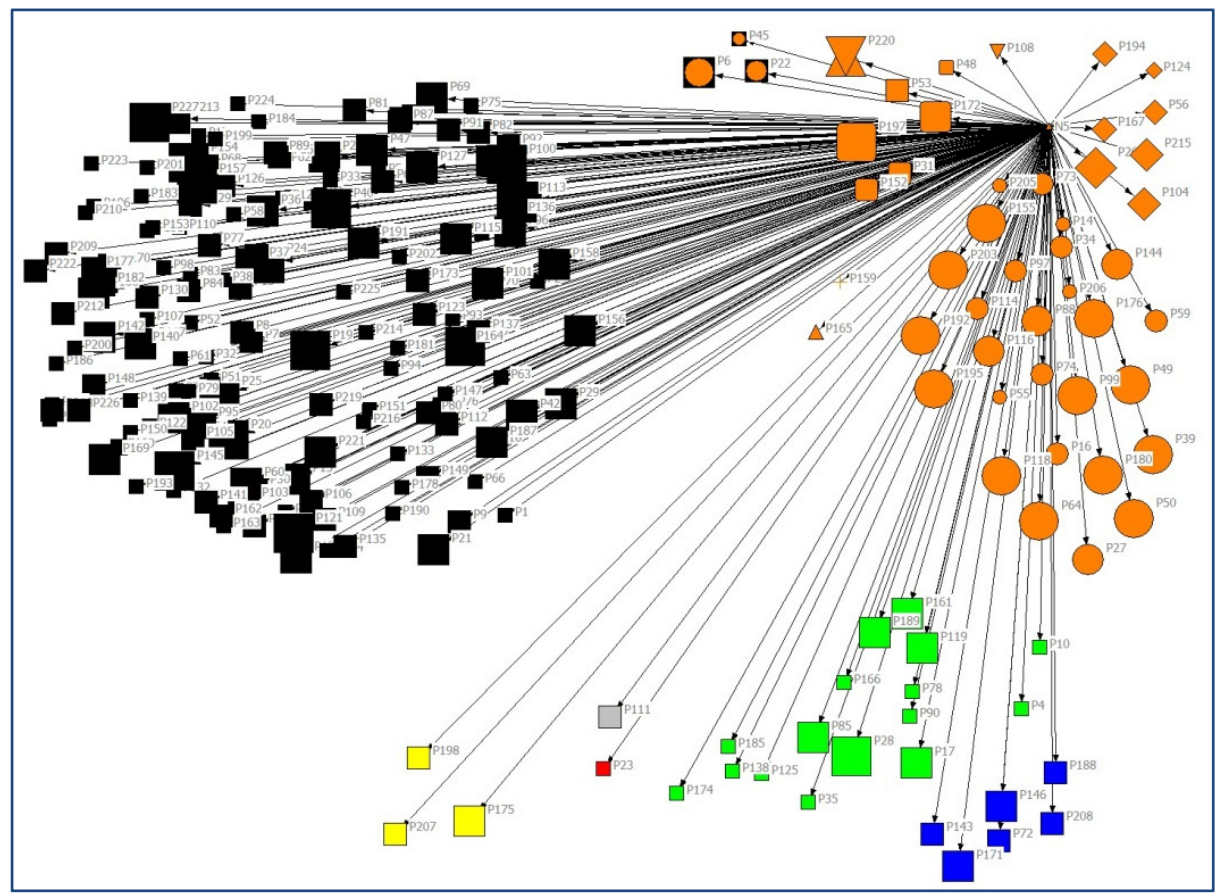

Figure 3. Ego network of N5 where the size of the symbol indicates the frequency of contact. Larger symbols indicate higher frequency of contact (as reported by the ego).

External contacts $\square$ Internal contacts are: BIS $\square$, NPWS $\square$, SPSG , Policy , Regional Operations . See text for acronyms.

Orange symbols are Science Division contacts. See Figure 4 for legend.

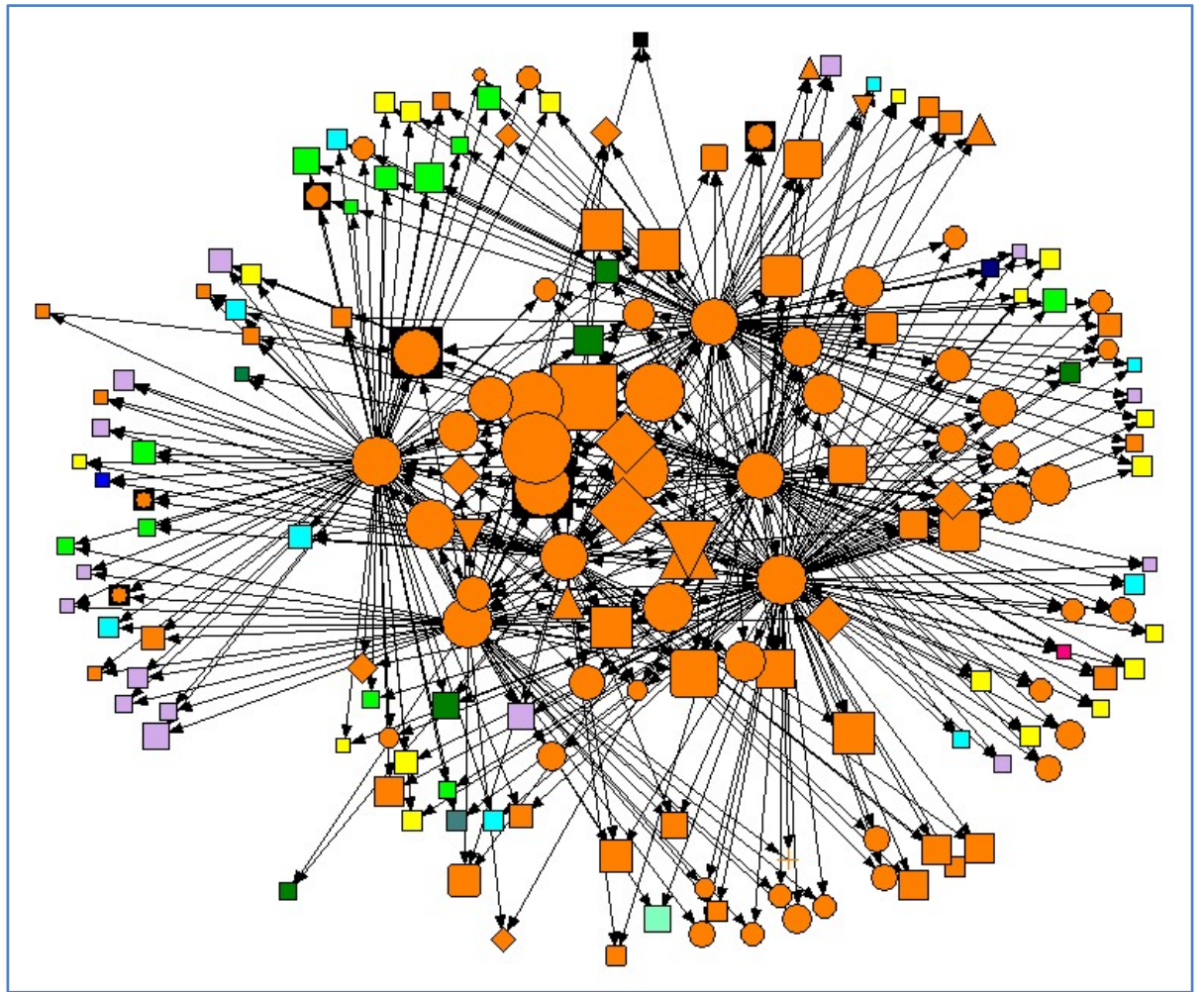

Figure 4. Stacked ego networks of six government scientists illustrating shared contacts from external organisations and $\mathrm{OEH}$. The size of symbol denotes frequency of contact (as in Figure 3). Pendants (a node connected to only one ego) have been removed for clarity.

External contacts are Australian Govt $\square$, Company

Consultant

Council

Cooperative Research Centre (CRC)

CSIRO

International _, Local Land Service $\square$,

Non-government organisation $\square$, Royal Botanic Garden Trust $\square$, Research $\square$, State Government $\square$, University . Contacts from OEH are . Contacts from OEH Science Division are: Climate \& Atmospheric Science $\triangle$; Divisional Coordination Strategy \& Performance $\square$, Ecosystem Management Science $\bigcirc$, Environment Protection Science $\nabla$, Executive Director $\downarrow$, Science Strategy $\diamond$, Vegetation Information

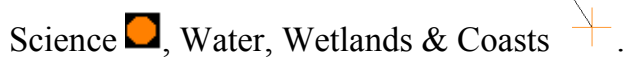


influenced policy had a diversity of contacts from a variety of categories, and acted as conduits for information from different sectors. This is likely to be the case for the six scientists in this study. To influence policy, Haynes et al. (2011) found researchers also need to be accessible and trusted, and understand the policy environment so they can provide balanced (contextualised) advice. We need to further explore the nature of the relationships between the scientists and staff from OEH Policy Division to determine the outcome from contact reported here.

The six scientists shared fewer contacts beyond their immediate colleagues in Science Division - either within the organisation or externally. According to Borgatti et al. (2009), "weak ties (e.g. mere acquaintances) can easily be unconnected to the rest of one's network and therefore more likely to be sources of novel information." The lack of overlap in external contacts suggests the six scientists could bring new ideas into existing networks.

The challenges of sharing information and knowledge between different disciplines such as science and policy are well documented (Gibbons et al. 2008). In theory, networks give rise to trust (Zaheer et al. 2010) and should promote the sharing of knowledge. However, Chua et al. (2008) found trust depends on why the contact develops. They found managers develop cognition-based trust in people they contact for information and advice to solve problems, but do not develop affect-based trust ("trust from the heart") in these people. Cognition-based trust ("trust from the head") does not necessarily result in knowledge sharing. We need to confirm the nature of ties developed by the scientists with their contacts, and determine whether contact results in knowledge sharing.

In this scoping study, we examined ego networks which analyse an individual's network from their point-of-view but recognise the contact may not share the perception of the ego (Kilduff and Tsai 2003). In future, we need to examine the network from the contact's point-of-view to determine whether reported interactions are reciprocated, and whether contact leads to knowledge sharing and, most importantly, flows into government policy, informs management of environmental threats and accesses novel information to solve environmental problems.

\section{CONCLUSION AND RECOMMENDATIONS}

In this scoping study, Social Network Analysis (SNA) has allowed six government scientists for the first time to visualise their networks so they could reflect on potential gaps and duplication in their own and across the group's networks, and the implications for themselves and the state government organisation in Australia. SNA also illustrated possible channels for the flow of the scientists' advice and knowledge to contacts within the organisation and beyond. Although we are yet to determine the significance of the number and diversity of contacts in their networks, this was a major benefit of this scoping study.

This study raised many questions which we are keen to pursue. These include determining whether the total number and diversity of contacts enhance the scientist's skills and capacity, as well as the reach and impact of their work. We also want to examine how SNA could be used to explore the social capital of scientists (as defined by Burt 2005, in Borgatti et al. 2009): how the position in social networks affected the "return on an actor's investment" in human capital (knowledge, ability, skills). We want to determine whether the scientists' perception is reciprocated by their contacts. Most importantly, we want to extend this work and determine whether contact results in sharing knowledge between disciplines and, ultimately, in better environmental protection.

\section{REFERENCES}

Benham, C., Hussey, K., and S. Beavis (2014). Planning for success in a climate change future: collaborative water governance in the Upper Murrumbidgee catchment, southeastern Australia. Australian Journal of Water Resources, 18, 1-14.

Borgatti, S.P. (2002). Netdraw Network Visualization. Analytic Technologies, Harvard, MA.

Borgatti, S.P., Everett, M.G., and L.C. Freeman (2002). UCINET 6 for Windows: Software for Social Network Analysis, Analytic Technologies, Harvard, MA.

Borgatti, S.P., Mehra, A., Brass, D.J., and G. Labianca (2009). Network analysis in the social sciences. Science, 323, 892-895.

Chua, R.Y.J., Ingram, P., and M.W. Morris (2008). From the head and the heart: locating cognition- and affectbased trust in managers' professional networks. Academy of Management Journal, 51(3), 436-452.

Crona, B.I., and J. Parker (2012). Learning in support of governance: theories, methods and a framework to assess how bridging organizations contribute to adaptive resource governance. Ecology and Society, 17, 32.

Cvitanovic, C., Clunn, R., Jacobs, B., Williams, C., and T. Measham (2014). Introduction to social networks for engaging communities in climate policy. Node for Adaptive Communities, Unpublished report to NSW Office of Environment and Heritage. 
Goggin et al., Exploring the networks of government scientists using Social Network Analysis: a scoping study

Dowd, A., Marshall, N., Fleming, A., Jakku, E., Gaillard, E., and M. Howden (2014). The role of networks in transforming Australian agriculture. Nature Climate Change, 4, 558-563.

Gibbons, P., Zammit, C., Youngentob, K., Possingham, H.P., Lindenmayer, D.B., Bekessy, S., Burgman, M., Colyvan, M., Considine, M., Felton, A., Hobbs, R.J., Hurley, K., McAlpine, C., McCarthy, M.A., Moore, J., Robinson, D., Salt, D., and B. Wintle (2008). Some practical suggestions for improving engagement between researchers and policy-makers in natural resource management. Ecological Management and Restoration, 9, 182-186.

Haynes, A.S., Gillespie, J.A., Derrick, G.E., Hall W.D., Redman, S., Chapman, S., and S. Sturk (2011). Galvanizers, guides, champions, and shields: the many ways that policy makers use public health researchers, The Milbank Quarterly, 89, 564-598.

Kilduff, M., and W. Tsai (2003). Social networks and organisations. SAGE Publications, London.

Long, J., Cunningham, F.C., and J. Braithwaite (2013). Bridges, brokers and boundary spanners in collaborative networks: a systematic review, BMC Health Services Research, 13, 158.

Roux, D.J., Kingsford, R.T., McCool, S.F., McGeoch, M.A., and L.C. Foxcraft (2015). The role and value of conservation agency research, Environmental Management, 55, 1232-1245.

Zaheer, A., Gozubukuk, R., and H. Milanov (2010). It's the connections: the network perspective in interorganizational research. The Academy of Management Perspectives, 24, 62-77.

Table 1. Total number of contacts of all egos, with number who were External and Internal (to OEH) (includes the egos), and the number who were Shared (by two or more egos). Categories are collapsed in this table, i.e., each State Government organisation (ACT, Qld, etc), type of research organisation (CRCs, CSIRO, etc) and type of university (overseas, Australian) are counted as separate categories when tallying contacts of the egos in Results. See Methods for acronyms.

\begin{tabular}{|l|c|c|c|c|c|}
\hline Categories (collapsed as in legend) & External & \multicolumn{2}{|c|}{ Internal (OEH) } & $\begin{array}{c}\text { Shared } \\
\text { contacts }\end{array}$ & Total \\
\hline External contacts & & & & & \\
\hline Company & 10 & & & 1 & \\
\hline Consultant & 57 & & & 9 & \\
\hline Council & 14 & & & 0 & \\
\hline Government: ACT; Qld; SA; TAS; VIC; WA; AUS; Intl & 87 & & & $\mathbf{6}$ & \\
\hline Government: NSW & 87 & & & 13 & \\
\hline International & 2 & & & 0 & \\
\hline Landholder & 2 & & & 0 & \\
\hline Local Land Services & 79 & & & 11 & \\
\hline Media & 3 & & & 0 & \\
\hline Non-government organisation & 27 & & & 1 & \\
\hline Professional organisations/ associations & 8 & & & 0 & \\
\hline Research: CRCs; CSIRO; Museums; RBGT; Researcher & 69 & & & 16 & \\
\hline Universities: all Australian universities; overseas & 235 & & & 14 & \\
\hline Volunteer & 11 & & & 0 & \\
\hline TOTAL External contacts & & & & $\mathbf{7 1}$ & $\mathbf{6 9 1}$ \\
\hline Internal (OEH) contacts & & Non Science & Science & & \\
\hline Business Information Systems & & 11 & & 3 & \\
\hline Chief Executive Officer & & 1 & & 0 & \\
\hline National Parks \& Wildlife Service & & 43 & & 4 & \\
\hline Policy Division & & 7 & & 1 & \\
\hline Regional Operations & & 66 & & 17 & \\
\hline Strategy, Performance \& Services Group & & & & 1 & \\
\hline Science Division & & $\mathbf{1 5 0}$ & $\mathbf{1 3 9}$ & & $\mathbf{2 8 9}$ \\
\hline TOTAL Internal (OEH) contacts & & & $\mathbf{2 8 9}$ & $\mathbf{9 8 0}$ \\
\hline TOTAL unique contacts for all egos & & 26 & 89 & 115 & 186 \\
\hline TOTAL shared contacts for all egos & & & \\
\hline
\end{tabular}

